\title{
Risk-Aversion and Prudence in Rent-Seeking Games
}

NICOLAS TREICH 


\title{
Risk-aversion and Prudence in Rent-seeking Games
}

\author{
Nicolas Treich ${ }^{* \dagger}$ \\ Toulouse School of Economics (LERNA, INRA), France
}

February 17, 2009

\begin{abstract}
This paper considers a common $n$-agent symmetric rent-seeking game. It derives conditions so that risk-aversion and risk always decrease rent-seeking efforts. These conditions hold for any regular contest success function when risk-averse rent-seekers are also prudent. Under $n=2$, prudence is a necessary and sufficient condition for risk-aversion to decrease rent-seeking efforts compared to risk-neutrality. An intuition for this result is given based on a self-protection model.
\end{abstract}

Keywords and phrases: Risk-aversion, Rent-seeking, Lobbying, Uncertainty, Prudence, Self-protection.

JEL Classification Numbers: C72, D72, D81.

${ }^{*}$ Full Address: LERNA-INRA, Toulouse School of Economics, Aile J.-J. Laffont, Manufacture des Tabacs, 21 Allées de Brienne, 31000 Toulouse, France. Email: ntreich@toulouse.inra.fr. Tel: +33561 1285 14. Fax: +33561 128520.

$\dagger$ I acknowledge Olivier Armantier, Guillaume Cheickbossian, Christian Gollier and Alexander Wagner, as well as conference participants at EGRIE 2008. 


\section{Introduction}

Rent-seeking activities like lobbying activities, job promotion efforts, R\&D competition, litigation expenditures, sports contests participation or arms races are risky activities. Rent-seekers exert efforts, or spend money, to increase the probability that they obtain a rent or a prize. Despite the risky nature of rent-seeking activities, most of the voluminous literature has studied rent-seeking games with risk-neutral agents (Tullock, 1980; Corcoran and Karels, 1985; Dixit, 1987; Perez-Castrillo and Verdier, 1992; Szidarowszky and Okuguchi, 1997; Hirshleifer, 2001; Malueg and Yates, 2005).

This paper examines the impact of risk-aversion in rent-seeking games. A handful of papers have examined this question. These papers have usually shown that risk-aversion decreases rent-seeking efforts. However, the results were obtained under restricted specifications. For instance, Hillman and Katz (1984) assume that the rent is "small" or present numerical simulations for a logarithmic utility function, and Skaperdas and Gan (1995) assume that the utility function displays constant absolute risk-aversion and that the contest success function is logistic with a power or exponential form. ${ }^{1}$ In fact, Konrad and Schlesinger (1997), using general concave utility and regular contest success functions, indicate that "it is possible for the contest with risk-averse players to dissipate more of the rents than the same contest with risk-neutral players" (Konrad and Schlesinger, 1997, p. 1677). This suggests that risk-aversion has in general an ambiguous effect on rent-seeking efforts.

In contrast, we demonstrate, using a similar model, that risk-aversion

\footnotetext{
${ }^{1}$ Also, Van Long and Vousden (1987) show that rent-seeking efforts (for a share of a divisible resource) decrease if and only if relative risk-aversion is larger than one.
} 
always decreases rent-seeking efforts compared to risk-neutrality. The additional condition that allows us to derive this result is that risk-averse rentseekers are also prudent. The condition of prudence is formally equivalent to a convex marginal utility function within the expected utility model, or $u^{\prime \prime \prime} \geq 0$ assuming differentiability. This condition induces a precautionary savings motive in life-cycle models (Leland, 1968; Kimball, 1990; Eeckhoudt, Gollier and Schlesinger, 2005). It is also well-known that the familiar assumption of decreasing absolute risk-aversion is equivalent to the coefficient of prudence $-u^{\prime \prime \prime} / u^{\prime \prime}$ larger than that of risk-aversion $-u^{\prime \prime} / u^{\prime}$. Standard concave utility functions, including the class of constant relative risk-aversion utility functions, therefore display prudence.

\section{The game and its properties}

The game is similar to that of Konrad and Schlesinger (1997). Consider $n \geq 2$ identical expected utility maximizers with initial wealth $w>0$ and with a strictly increasing, thrice differentiable and concave von Neumann Morgernstern utility function $u($.$) . These agents compete for a rent b>$ 0 . For any rent-seeker $i$, the probability to get the rent $b$ is denoted $p_{i} \equiv$ $p_{i}\left(x_{1}, \ldots, x_{n}\right)$ in which $x_{j}, j=1, \ldots, n$, is the agent $j$ 's rent-seeking effort. We assume that the contest success function $p_{i}$ is continuously differentiable.

Following Konrad and Schlesinger (1997, p. 1674), we make the following assumptions on the contest success function. For all $i$ and all $j \neq i$, we 
assume:

$$
\begin{aligned}
\text { A1 }: & \frac{\partial p_{i}}{\partial x_{i}}\left(x_{1}, \ldots, x_{n}\right) \geq 0 \text { and } \frac{\partial p_{i}}{\partial x_{j}}\left(x_{1}, \ldots, x_{n}\right) \leq 0, \text { for all } x_{i} \in[0, w], \\
\text { A2 }: & \frac{\partial^{2} p_{i}}{\partial x_{i}^{2}}(x, \ldots, x)<0, \text { for all } x \in[0, w] \\
\text { A3 }: & \frac{\partial^{2} p_{i}}{\partial x_{j} \partial x_{i}}(x, \ldots, x) \leq 0, \text { for all } x \in[0, w] \\
\text { A4 }: & p_{i}(x, \ldots, x)=1 / n \text { for all } x \in[0, w] .
\end{aligned}
$$

A1 states that the probability to get the rent increases in one's own rentseeking effort, and decreases in the effort of the opponent(s). A2 and A3 reflect common assumptions about decreasing marginal returns of effort. Finally, A4 states that if all rent-seekers exert the same level of effort, they have the same probability to get the rent.

In this model, agent $i$ 's expected utility therefore equals

$$
p_{i} u\left(w+b-x_{i}\right)+\left(1-p_{i}\right) u\left(w-x_{i}\right),
$$

in which the strict concavity of $u$ characterizes risk-aversion.

One difficulty in a rent-seeking game with risk-averse agents is to characterize the existence of the equilibrium. Under $n=2$, and under constant absolute risk-aversion, Skaperdas and Gan (1995) show that an equilibrium exists. Assuming a logistic contest success function, ${ }^{2}$ Cornes and Hartley (2003) generalize this result to $n$ agents but still under constant absolute

\footnotetext{
${ }^{2} \mathrm{~A}$ logistic contest success function is characterized by $p_{i}=\frac{\Phi\left(x_{i}\right)}{\sum_{j=1}^{n} \Phi\left(x_{j}\right)}$. It is commonly assumed that $\Phi$ is continous, twice differentiable with $\Phi(0)=0, \Phi^{\prime}(x)>0$ and $\Phi^{\prime \prime}(x) \leq 0$ for $x>0$. Under these assumptions, A1 to A4 are satisfied, except at the origin $(0, \ldots, 0)$ where derivatives do not exist.
} 
risk aversion, and Cornes and Hartley (2008) have recently demonstrated that an equilibrium always exists for any concave utility function.

Another difficulty concerns the possibility of multiple equilibria under risk-aversion. Cornes and Hartley (2003) demonstrate that the equilibrium is unique in an asymmetric contest where the absolute risk-aversion coefficient is constant. Cornes and Hartley (2008) relax the assumption of constant absolute risk-aversion, and show that the symmetric equilibrium is unique in a symmetric contest. For an asymmetric contest, Cornes and Hartley (2008) identify some conditions on the utility function and on the size of the rent which insures uniqueness, and Yamazaki (2008) demonstrates uniqueness under decreasing absolute risk-aversion. We note, however, that these last three papers assume logistic contest success functions.

We now derive some conditions, for the general class of contest success functions introduced above, under which the symmetric equilibrium is unique:

Proposition 1 Under $A 1$ to A4, there is a unique symmetric equilibrium under decreasing absolute risk-aversion for a "small" rent $b$.

This Proposition is demonstrated in the Appendix. The proof in the Appendix first identifies a general sufficient condition on the utility function that insures that the symmetric equilibrium is unique. This condition does not depend on the contest success function and is always satisfied under constant absolute risk-aversion for any $b$. When $b$ is small enough in the sense of a second order Taylor approximation around 0, this condition is always satisfied under decreasing absolute risk-aversion, as stated in Proposition 1. 


\section{The effect of risk-aversion on rent-seeking efforts}

Our objective is to compare in our symmetric game the rent-seeking efforts made by risk-averse agents to those made by risk-neutral agents. We denote $p_{x}$ the partial derivative $\partial p_{i} / \partial x_{i}$ evaluated at $(x, \ldots, x)$, that is identical across individuals by symmetry. Under A4, the equilibrium condition is

$$
F(x)=p_{x}[u(w+b-x)-u(w-x)]-\left[\frac{1}{n} u^{\prime}(w+b-x)+\left(1-\frac{1}{n}\right) u^{\prime}(w-x)\right]=0
$$

which, under risk-neutrality, reduces to

$$
f(x) \equiv p_{x} b-1=0
$$

Observe that $f(x)$ is strictly decreasing in $x$ under A2 and A3. The symmetric equilibrium under risk-neutrality is thus unique. It is then direct that $f(x)$ positive (negative) at any $x$ solution to (2), implies that rent-seeking efforts under risk-aversion are lower (larger) than under risk-neutrality. We notice that if there are multiple symmetric equilibria under risk-aversion, ${ }^{3}$ the proof below derives the conditions so that every symmetric equilibrium under risk-aversion is below (or above) the (unique) symmetric equilibrium under risk-neutrality.

Proposition 2 Under A1 to A4, risk-aversion decreases rent-seeking efforts under prudence.

\footnotetext{
${ }^{3}$ This is not possible if the rent is "small" under decreasing absolute risk-aversion (see Proposition 1).
} 


\section{Proof:}

Using (3), $f(x)$ positive at any $x$ solution to (2) is equivalent to

$$
g(b)=\left[\frac{1}{n} u^{\prime}(w+b-x)+\left(1-\frac{1}{n}\right) u^{\prime}(w-x)\right] b-[u(w+b-x)-u(w-x)] \geq 0
$$

To prove (4), we use the following Lemma.

Lemma 1 (Eeckhoudt and Gollier, 2005, Lemma 1). Let

$$
H(A, B)=0.5\left[u^{\prime}(B)+u^{\prime}(A)\right](B-A)-[u(B)-u(A)] \text { with } A \leq B
$$

The function $H$ is positive (resp. negative) in its domain if and only if $u^{\prime}$ is convex (resp. concave).

This Lemma simply states than when $u^{\prime}$ is convex the area under its graph is smaller than the area under its chord from $A$ to $B$.

The proof that (4) holds assuming $u^{\prime}$ convex is then straightforward. Indeed, we have

$$
\begin{aligned}
& {\left[\frac{1}{n} u^{\prime}(w+b-x)+\left(1-\frac{1}{n}\right) u^{\prime}(w-x)\right] b } \\
\geq & {\left[\frac{1}{2} u^{\prime}(w+b-x)+\frac{1}{2} u^{\prime}(w-x)\right] b } \\
\geq & {[u(w+b-x)-u(w-x)] }
\end{aligned}
$$

where the first inequality holds since $n \geq 2$ and $u^{\prime}$ is decreasing, and the last inequality holds by (5) with $B=w+b-x$ and $A=w-x$, and $u^{\prime}$ convex.

\section{Q.E.D}

This shows that $u^{\prime}$ convex is sufficient for risk-averse rent-seekers to reduce their efforts. Moreover, under $n=2$, the second inequality (7) above 
reduces to an equality, and $u^{\prime}$ convex becomes a necessary and sufficient condition. Indeed, if $u^{\prime}$ is locally concave, it is possible to find well-chosen parameters $w, x$ and $b$ so that the last inequality (8) is reversed, and therefore rent-seeking efforts increase with risk-aversion.

Corollary 1 Under $A 1$ to $A 4$, and under $n=2$, risk-aversion decreases rent-seeking efforts if and only if rent-seekers are prudent.

This implies that risk-aversion has no effect on rent-seeking efforts under a (concave) quadratic utility function (where $u^{\prime \prime \prime}=0$ ) when $n=2$, as shown in the following example.

Example 1 Assume $n=2, u(z)=-(1-z)^{2}$ with $z \in[0,1]$ and $p_{i}\left(x_{1}, x_{2}\right)=$ $x_{i} /\left(x_{1}+x_{2}\right), i=1,2$. The unique zero of $F(x)$ in (2) is $b / 4$. Under riskneutrality, the equilibrium rent-seeking effort is also equal to b/4. Hence the rent-seeking effort at the equilibrium under risk-aversion is equal to that under risk-neutrality.

Moreover, previous results imply that risk-aversion together with failure of prudence increases, and not decreases, rent-seeking efforts under $n=2$. This seems inconsistent with the early result of Hillman and Katz (1984) that risk aversion always decreases rent-seeking efforts for a "small" rent. Indeed Corollary 1 holds for any rent $b$, including "small" ones. To understand this result, let us further examine the sign of $g(b)$ in (4), but for a "small" $b$. It is easy to obtain that $g(0)=0, g^{\prime}(0)=0$ and $g^{\prime \prime}(0)=\frac{(n-2)}{n}\left[-u^{\prime \prime}(w-\right.$ 
$x)$ ]. Therefore under risk-aversion, $g(b)$ is always positive for a "small" $b$, consistent with Hillman and Katz (1984). Yet $g^{\prime \prime}(b)=0$ under $n=2$, indicating that the effect of risk-aversion is negligible for a "small" rent. ${ }^{4}$

The previous discussion suggests that the case $n=2$ is a limit case for the result. This relates to the observation that the probability $p=1 / 2$ is a critical probability threshold in self-protection models (Dachraoui et al., 2004; Eeckhoudt and Gollier, 2005). To understand why, consider the expected utility

$$
E u(B-\widetilde{z})=p u(B)+(1-p) u(B-b)
$$

where $\widetilde{z}$ therefore takes 0 with probability $p$ and $b$ with probability $1-p$. An increase in $p$ is then similar to an investment in self-protection as it increases the probability of the favorable state. Observe now that the variance of $\widetilde{z}$ is equal to $p(1-p) b^{2}$. Therefore self-protection increases, and not decreases, the variance of $\widetilde{z}$ when $p \leq 1 / 2$. Recall that, in a symmetric rent-seeking games, we can only have $p \leq 1 / 2$ at the equilibrium, a stark difference compared to self-protection models. As a result, it is not surprising that risk-averse rentseekers are more reluctant to increase $p$ compared to risk-neutral rent-seekers since this increases the variance of their terminal payoff.

\footnotetext{
${ }^{4}$ This is consistent with the results displayed Table 2 in Hillman and Katz (1984). Their numerical simulations using a logarithmic utility function show that rent dissipation is equal to $50 \%$ for $n=2$ and for low values of the rent (i.e., $10 \%$ and $20 \%$ of initial wealth); namely, rent dissipation is (approximately) equal to that under risk neutrality.
} 


\section{The effect of a risky rent under risk-aversion}

There may be various sources of uncertainty in rent-seeking activities beyond the uncertainty over who wins. There is a need to study more systematically the effect of risk-aversion in such uncertain environments, as recently observed by Garfinkel and Skaperdas (2007).

In this section, we follow Wärneryd (2003), and assume that the rent is risky. That is, we assume that the rent $\widetilde{b}$ is a random variable, with $E \widetilde{b}=b$. Wärneryd (2003) considers a model with risk-neutral agents, and examines the effect of asymmetric information about the value of the rent. In our model, since there is no information asymmetry, uncertainty over the rent would have no effect on the equilibrium under risk-neutrality. The interesting situation is when risk aversion is introduced.

First, to make the problem interesting, we assume that the risky rent is desirable despite risk-aversion. The first-order condition for an interior symmetric equilibrium therefore becomes:

$G(x)=p_{x}[E u(w+\widetilde{b}-x)-u(w-x)]-\left[\frac{1}{n} E u^{\prime}(w+\widetilde{b}-x)+\left(1-\frac{1}{n}\right) u^{\prime}(w-x)\right]=0$

To examine the effect of risk, we compare this last expression to (2), that is, we compare $G(x)$ to $F(x)$. Using Jensen's inequality, observe that $E u(w+\widetilde{b}-x)$ is lower than $u(w+b-x)$ under risk aversion, and that $-E u^{\prime}(w+\widetilde{b}-x)$ is lower than $-u^{\prime}(w+b-x)$ under prudence. Consequently, $G(x)$ is below $F(x)$ for all $x$ under risk-aversion and prudence. Hence, if the symmetric equilibrium is unique, the introduction of risk decreases rentseeking efforts. ${ }^{5}$ The leads to the following Proposition.

\footnotetext{
${ }^{5}$ Under constant absolute risk-aversion, we prove in the appendix that the symmetric
} 
Proposition 3 Suppose that the symmetric equilibrium characterized by (9) is unique. Then risk-averse and prudent rent-seekers exert less efforts when the rent is risky.

The intuition is that risk decreases the marginal benefit of winning the rent under risk-aversion, and increases the marginal cost of spending money under prudence. Both effects put a downward pressure on rent-seeking efforts at the equilibrium.

The introduction of risk over the value of the rent has thus two effects on expected utility. First, keeping rent-seekers' efforts constant, it decreases expected utility under risk-aversion. Second, it reduces rent-seeking efforts under risk-aversion and prudence. Hence, if the positive effect of the last strategic effect is large enough, it is theoretically possible that risk increases the expected utility of risk-averse rent-seekers at the equilibrium. The following numerical example based on constant absolute risk-aversion shows, however, that the first risk-aversion effect dominates the second strategic effect.

Example 2 Assume $n=2, u(z)=-\exp (-z)$ and $p_{i}\left(x_{1}, x_{2}\right)=x_{i} /\left(x_{1}+x_{2}\right)$, $i=1,2$. Assume also that $\widetilde{b}$ is equal to $b+\theta$ or $b-\theta$ with equal probability. The optimal equilibrium rent-seeking effort under certainty, i.e. when $\theta=$ 0 , is equal to $\frac{\exp b-1}{2(1+\exp b)}<b / 4$. The optimal equilibrium rent-seeking effort equilibrium is unique, even under a risky rent. Moreover, if there are multiple equilibria, the lowest and the highest symmetric equilibria are lower under risk than under certainty. For more details on the comparative statics of multiple equilibria, see, e.g., Milgrom and Roberts (1994). 
under risk is equal to $\frac{2 \exp (b+\theta)-\exp (2 \theta)-1}{2(1+\exp (2 \theta)+2 \exp (b+\theta))}$, which decreases in $\theta(\theta \geq 0)$ and is therefore lower than $\frac{\exp b-1}{2(1+\exp b)}$, consistent with Proposition 3. Then plugging equilibrium rent-seeking effort under risk into expected utility shows that welfare decreases in $\theta$.

\section{Conclusion}

In this paper, we have derived two main results. First, we have shown that risk-averse and prudent rent-seekers always exert less efforts compared to risk-neutral rent-seekers. A natural follow-up of this work would be study the more difficult case of heterogeneous rent-seekers, using more general utility and contest success functions than in existing studies (Skaperdas and Gan, 1995; Cornes and Hartley, 2003). Interestingly, Cornes and Hartley (2008) have recently derived general conditions so that risk-aversion decreases rentseeking efforts in asymmetric contests with a logistic contest success function. Cornes and Hartley's results nevertheless depend on whether the equilibrium probability is lower or larger than $1 / 2$. This is not surprising since $1 / 2$ is a pivotal probability to sign the effect of risk-aversion in self-protection models (Eeckhoudt and Gollier, 2005). The links between rent-seeking games and self-protection models also suggest that the effect of "more risk aversion" à la Pratt (1964) should depend on complex conditions on the utility and/or probability functions (Jullien, Salanié and Salanié, 1999; Dachraoui et al., 2004).

Second, we have shown that risk-averse and prudent rent-seekers exert less efforts when the rent is risky. This is because risk decreases the marginal 
benefit of receiving the rent under risk-aversion, and increases the marginal cost of exerting efforts under prudence. Moreover, we have provided a numerical example in which risk decreases welfare despite the overall reduction of rent-seeking expenditures at the equilibrium. This suggests a few directions for future research. It could be interesting for instance to identify general conditions insuring a systematic negative/positive effect of risk on welfare in rent-seeking games, as it has been done in other strategic environments (Eso and White, 2004; Bramoullé and Treich, 2007). Moreover, it could be interesting to study how risk affects the incentive to engage in rent-seeking activities in a model where entry is possible. 


\section{Appendix}

In this appendix, we provide sufficient conditions for the uniqueness of the symmetric equilibrium under risk-aversion, which is characterized by (2):

$F(x)=p_{x}[u(w+b-x)-u(w-x)]-\left[\frac{1}{n} u^{\prime}(w+b-x)+\left(1-\frac{1}{n}\right) u^{\prime}(w-x)\right]=0$

The symmetric equilibrium is unique if $F(x)=0 \Rightarrow F^{\prime}(x)<0$. We obtain

$$
\begin{aligned}
F^{\prime}(x)= & \frac{d p_{x}}{d x}[u(w+b-x)-u(w-x)]-p_{x}\left[u^{\prime}(w+b-x)-u^{\prime}(w-x)\right]+ \\
& {\left[\frac{1}{n} u^{\prime \prime}(w+b-x)+\left(1-\frac{1}{n}\right) u^{\prime \prime}(w-x)\right] }
\end{aligned}
$$

in which the first term $\frac{d p_{x}}{d x}[u(w+b-x)-u(w-x)]$ is strictly negative under our assumptions A2 and A3 on the contest success function. Hence, a sufficient condition to get uniqueness of the symmetric equilibrium is

$$
p_{x}\left[u^{\prime}(w+b-x)-u^{\prime}(w-x)\right]-\left[\frac{1}{n} u^{\prime \prime}(w+b-x)+\left(1-\frac{1}{n}\right) u^{\prime \prime}(w-x)\right] \geq 0
$$

Replacing $p_{x}$ by its value given by (2) above, and denoting $A=w-x$, this last inequality becomes

$$
\begin{aligned}
t(b)= & {\left[u^{\prime}(A+b)-u^{\prime}(A)\right]\left[\frac{1}{n} u^{\prime}(A+b)+\left(1-\frac{1}{n}\right) u^{\prime}(A)\right]-} \\
& {[u(A+b)-u(A)]\left[\frac{1}{n} u^{\prime \prime}(A+b)+\left(1-\frac{1}{n}\right) u^{\prime \prime}(A)\right] } \\
\geq & 0
\end{aligned}
$$

This inequality provides a sufficient condition on $u$ for the uniqueness of the equilibrium for all $n, b$ and $A$. Again, observe that this condition is independent from the contest success function.

We first discuss the case of constant absolute risk-aversion. Assume $u(z)=-\exp (-\lambda z)$. We have i) $u^{\prime}(z)=-\lambda u(z)$ and ii) $u^{\prime \prime}(z)=\lambda^{2} u(z)$. The 
inequality (10a) then becomes an equality, so that $F^{\prime}(x)<0$. Hence, there is a unique symmetric equilibrium under constant absolute risk-aversion. This result is consistent with Cornes and Hartley (2003). Moreover, it is easy to show that the symmetric equilibrium is also unique when the rent is risky, a result which is relevant for section 4 . To prove this, simply observe that (2) above holds where $u$ is an indirect utility function defined by $u(z+b)=E u_{0}(z+\widetilde{b})$ and $E \widetilde{b}=b$. The result is immediate since the properties i) and ii) on the indirect utility function $u$ just defined are preserved if $u_{0}(z)=-\exp (-\lambda z)$.

Finally, we demonstrate Proposition 1. We prove that $t(b)$ in (10a) is always positive for $b$ sufficiently close to 0 . Indeed by differentiation of $t(b)$ it is straightforward to obtain $t(0)=0, t^{\prime}(0)=0$ and

$$
t^{\prime \prime}(0)=\frac{n-2}{n}\left(u^{\prime}(A) u^{\prime \prime \prime}(A)-u^{\prime \prime}(A)^{2}\right)
$$

Therefore $t^{\prime \prime}(0)$ has the sign of $\left(\frac{u^{\prime \prime \prime}(A)}{-u^{\prime \prime}(A)}-\frac{u^{\prime \prime}(A)}{-u^{\prime}(A)}\right)$, which is positive for all $n \geq 2$ if and only if $u$ has decreasing absolute risk-aversion. 


\section{References}

Bramoullé, Yann and Nicolas Treich, 2007, Can uncertainty alleviate the commons problem?, Journal of the European Economic Association, forthcoming.

Corcoran, William J. and Gordon V. Karels, 1985, Rent-seeking behavior in the long-run, Public Choice, 46, 227-46.

Cornes, Richard and Roger Hartley, 2003, Risk aversion, heterogeneity and contests, Public Choice, 117, 1-25.

Cornes, Richard and Roger Hartley, 2008, Risk aversion in symmetric and asymmetric contests, mimeo.

Dachraoui, Kais, Dionne, George, Eeckhoudt, Louis and Philippe Godfroid, 2004, Comparative mixed risk aversion: Definition and application to self-protection and willingness to pay, Journal of Risk and Uncertainty, 29, 261-276.

Dixit, Avinash, 1987, Strategic behavior in constests, American Economic Review, 77, 891-98.

Eeckhoudt, Louis and Christian Gollier, 2005, The impact of prudence on optimal prevention, Economic Theory, 26, 989-994.

Eeckhoudt, Louis, Gollier, Christian and Harris Schlesinger, 2005, Economic and Financial Decisions under Risk, Princeton University Press.

Eso, Peter and Lucy White, 2004, Precautionary bidding in auctions, Econometrica, 72, 77-92.

Garfinkel, Michelle R. and Stergios Skaperdas, 2007, Economics of conflict: An overview, in T. Sandler and K. Hartley (eds.), Handbook of Defense Economics, Vol. II, 649-709. 
Hillman, Arye L. and Eliakim Katz, 1984, Risk-averse rent seekers and the social cost of monopoly power, Economic Journal, 94, 104-110.

Hirshleifer, Jack, 2001, The Dark Side of the Force, Cambridge University Press.

Jullien, Bruno, Salanié, Bernard and François Salanié, 1999, Should more risk-averse agents exert more efforts?, Geneva Papers on Risk and Insurance Theory, 24, 19-28.

Kimball, Miles, 1990, Precautionary savings in the small and in the large, Econometrica, 58, 53-73.

Konrad, Kai A. and Harris Schlesinger, 1997, Risk aversion in rent-seeking and rent-augmenting games, Economic Journal, 107, 1671-1683.

Leland, Hayne E., 1968, Savings and uncertainty: The precautionary demand for saving, Quarterly Journal of Economics, 45, 621-36.

Malueg, David A. and Andrew Yates, 2005, Equilibria and comparative statics in two-player contests, European Journal of Political Economy, 21, $738-52$.

Milgrom, Paul and John Roberts, 1994, Comparing equilibria, American Economic Review, 84, 441-459.

Pratt, John W., 1964, Risk aversion in the small and in the large, Econometrica, 32, 122-36.

Perez-Castrillo, David J. and Thierry Verdier, 1992, A general analysis of rent-seeking games, Public Choice, 73, 335-50.

Skaperdas, Stergios and Li Gan, 1995, Risk aversion in contests, Economic Journal, 105, 951-62.

Szidarowszky, Ferenc and Koji Okuguchi, 1997, On the existence and 
uniqueness of pure Nash equilibrium in rent-seeking games, Games and Economics Behavior, 18, 135-40.

Tullock, Gordon, 1980, Efficient rent-seeking, in J.M. Buchanan, R.D. Tollison and G. Tullock, Toward a Theory of the Rent-seeking Society, Texas A. \& M. University Press, College Station, 97-112.

Van Long, Ngo and Neil Vousden, 1987, Risk-averse rent seeking with shared rents, Economic Journal, 971-85.

Wärneryd, Karl, 2003, Information in conflicts, Journal of Economic Theory, 121-136.

Yamazaki, Takeshi, 2008, The uniqueness of pure-strategy Nash equilibrium in rent-seeking games with risk-averse players, Public Choice, forthcoming. 